\title{
Application of the Outcome Present State Test Model in a Patient with Liver Cirrhosis: A Case Study
}

\author{
Andréa Cristina Leite Nogueira, $\mathbf{R N}^{1}$, Patrícia Costa dos Santos da Silva, PhD, $\mathbf{R N}^{2}$, Eugenia Velludo Veiga, \\ PhD, RN ${ }^{1}$, Rebecca O. Shasanmi, MPH, BSN ${ }^{3}$, Fernanda Raphael Escobar Gimenes, PhD, RN ${ }^{1}$ \\ ${ }^{1}$ University of São Paulo at Ribeirão Preto College of Nursing, WHO Collaborating Centre for Nursing Research \\ Development, Ribeirão Preto, São Paulo, Brazil \\ ${ }^{2}$ Federal University of Alfenas, Alfenas, Minas Gerais, Brazil \\ ${ }^{3}$ Nursing and Public Health Research, Philadelphia, Pennsylvania, United States of America
}

\begin{abstract}
This paper presents the case study of a 74 year old man with liver cirrhosis and consumptive syndrome. Data was collected in a Brazilian university hospital. The case study approach used was outcomepresent state test (OPT) model. The assessment was made by using the Conceptual Model of Wanda Horta. Also, the NANDA-I, Inc., Nursing Outcomes Classification (NOC), and Nursing Interventions Classification (NIC) linkages were used to capture accurate nursing care plan. The keystone nursing diagnosis was: Imbalanced nutrition: less than body requirements. The NOC outcomes chosen were Nutritional Status: Food and Fluid Intake; and Weight: Body Mass Control. The NIC interventions chosen for the patient were: Enteral Tube Feeding and Fluid Monitoring. The findings support that the use of a clinical reasoning web helps nurses to identify the priority focus of care in patients with complex health problem, and to prevent future complications associated with the evolution of disease. Future researches are needed to determine the NANDA-I, NOC, and NIC linkages based on a clinical reasoning model to capture accurate nursing care plan for all patients with chronic condition, in order to provide competent and safe care, thus improving patient outcomes.
\end{abstract}

Keywords: Nursing Process, Nursing Assessment, Clinical Reasoning, OPT Model, Liver Cirrhosis

\section{INTRODUCTION}

Liver cirrhosis is a chronic condition related to the destruction of normal liver structure and architecture, with fibrosis, characterized by hepatic nodules separated by fibrous tissue ${ }^{1}$. Liver cirrhosis is a condition with high incidence, $\mathrm{n}$, with more than one million deaths in $2010^{2}$, thus the disease is a serious public health problem. There are numerous complications related to the disease process, which have a negative impact on a person's quality of life. These complications include impaired lung function, ascites, hepatic encephalopathy, jaundice, decreased muscle mass and function, portal hypertension, and heart problems ${ }^{3-5}$.

There is no treatment able to eradicate the disease; therefore the goal is to halt the progression of the disease and to prevent the development of complications. Changes in eating habits and the abolition of alcohol are needed. The therapy is aimed at improving the nutritional status via nutritional supplements, vitamins and high-protein food, except in the presence of hepatic encephalopathy. Some drugs such as diuretics, antacids and antibiotics are also used. In this context, nurses plays a key role in the comprehensive and continuous care to the patients with liver cirrhosis because nurses need to make decisions based on the information and skills of critical thinking, which is necessary for accurate data collection and interpretation of relevant information on the health status of the patient ${ }^{6}$.

\section{THE CASE}

The patient was a 74 years old black man, single, illiterate, who lived with two brothers in a brick house with basic sanitation. Patient was admitted to the gastroenterology ward of a Brazilian university hospital for treatment of liver cirrhosis due to alcohol (Child B8), refractory ascites with spontaneous bacterial peritonitis, consumptive syndrome, severe malnutrition, and diarrhea.

Liver cirrhosis is the final step of a process that arises as a result of numerous diseases, especially alcoholic liver disease and viral hepatitis; in addition it is considered a major cause of death worldwide ${ }^{7-10}$. In Brazil, studies focused on the etiology and mortality from liver cirrhosis is scarce ${ }^{10-12}$. However, it is known that the prevalence of liver cirrhosis has increased in the Brazilian population, especially among the elderly. Cirrhosis is the eighth leading cause of death among men, and contributed to $8.95 \%$ of hospital admissions in $2010^{13-16}$. Thus, liver cirrhosis has been highlighted in the literature, given its high prevalence and chronicity ${ }^{17,18}$. 
The present study is necessitated by the lack of publications addressing the nursing diagnoses in clinical patients with liver cirrhosis in Brazil and worldwide. Several studies identified the most frequent nursing diagnoses in different populations, but none in patients with liver cirrhosis ${ }^{19-22}$. In addition, few studies of clinical reasoning have been conducted in a practice setting ${ }^{23}$, and no studies focusing on clinical reasoning in patients with liver cirrhosis where published. The impetus of the study is to identify the priority focus of care for patients with a chronic condition using a clinical reasoning web, with the aims of reducing patients' length of stay, the risks associated with healthcare, and to improve patient's outcomes.

\section{THE NURSING ASSESSMENT}

A case study was conducted in a Brazilian University Hospital, in São Paulo state in March 2013. The study was approved by the appropriate ethics committee. Patient was assured that identity would remain confidential and signed a consent form voluntarily. A systematic data collection was conducted and it included interaction, observation, and measurement. Data was also collected from other resources, including family and significant others, medical records, results of diagnostic tests, nursing notes, change of shift reports, and health team members. The tool used for data collection was developed by the investigators and it was based on the Conceptual Model of Wanda Horta ${ }^{24}$, the first nurse to introduce the concept of nursing process in Brazil. This model is based on the concept of the Hierarchy of Basic Human Needs proposed by Maslow ${ }^{25}$, which influence human behavior.

The patient reported that return to hospital gastroenterology clinic was to carry out relief paracentesis. Patient presented with diarrhea for the past four days, postprandial vomiting and anorexia with loss of $10 \mathrm{~kg}$ in the last four months. On admission, patient was disoriented, sleepy, and with important dehydration. Patient denied allergies and family history of diabetes and cardiovascular disease. Previously a smoker, having quit smoking four months ago; drank large amounts of alcohol for several years, but stopped six years ago. In relation to the usual pattern of eating, patient ate three large meals, had low intake of fruits and no vegetables. Self-reported drinking too little water, but could not say how much; usual standard of urinary elimination was three times daily, bowel movements were three to four times per day, and the feces were soft. Patient did not know usual medications. On physical examination, the patient was eupneic, with decreased breath sounds and presence of crackles in bases; normotensive but with arrhythmic pulse; presence of edema in the lower limbs with locker; abdominal anomalous collateral circulation. Patient had flexible peripheral venous catheter and was receiving intravenous albumin, presented normothermic, conscious, lethargic, complaining of discomfort in the lower arch due to sore buccal cavity. The skin and mucous membranes were pale, with bruises on the upper limbs, stage II pressure ulcer in sacral region and perianal fissures; moisture, mobility and elasticity of the skin were decreased, the nails had uneven surface, opaque, and brittle. The patient lost $21 \%$ of the weight in five months, with an average arm circumference of $15 \mathrm{~cm}$ and triceps skinfold of $4 \mathrm{~mm}$, revealing extreme thinness. Diet was given orally without fluid restriction, but with positive water balance in the last three days. Patient presented with diarrhea, abdominal as cites and underwent relief paracentesis. Patient was bedridden and needed help for bathing, dressing, eating, had bilateral muscle weakness and decreased muscle mass. Patient communicated verbally with tone low and weak voice.

\section{Data Analysis}

The constant changes in clinical status of patients with liver cirrhosis require quick and assertive decision-making. With the aim of providing quality care, nurses have joined forces to build a body of knowledge focused on evidencebased practices to provide competent and safe care. In this context, experts agree that a new model of thinking are needed to facilitate rapid, accurate, and strategic care planning processes and care delivery for patients with complex health problem in a complex and technological environment ${ }^{26}$. The Outcome-Present State-Test (OPT) model of clinical reasoning is described as the third-generation nursing process model and it emphasizes reflections, outcome specification and testing. Thus, the model shifts the nursing process from being problem orientated to outcome orientated $^{27-29}$.

There are multiple concepts that have been used as synonymous for clinical reasoning. However, the concepts of clinical reasoning and diagnostic reasoning focus on the thinking strategies that a nurse uses to make a judgment or decision to solve problems. Thus, clinical reasoning in nursing can be defined as "a complex cognitive process that uses formal and informal thinking strategies to gather and analyses patient information, evaluate the significance of this information, and determine the value of alternative actions" ${ }^{\prime 30}$.

The OPT model also provides a conceptual structure for standardized languages. For example, the "present state" is defined as NANDA International, Inc. (NANDA-I) diagnosis; while outcomes serve as desired states and are 
defined in terms of NOC (Nursing-Sensitive Outcomes Classification). Finally, the nursing actions that help patients to transition from problems state to desirable outcome states are defined as NIC (Nursing Interventions Classification). All the standardized nursing language (NANDA-I, NOC, NIC) represent relationships between and among nursing diagnosis, interventions and outcomes ${ }^{28,31}$.

The application of the OPT model starts with creating a clinical reasoning web that enables nurses to determine multiple nursing diagnoses relationships, through the identification of the keystone problem or the priority focus of care. In this sense, nurses are able to note the nursing diagnosis with the most arrows in the web supporting that this diagnosis has an impact on the other related diagnoses in the patient's situation ${ }^{32}$. Explaining relationships among nursing diagnosis supports the development of clinical reasoning skills ${ }^{33}$. The priority focus of care for the patient was identified using a clinical reasoning web (Figure 1).

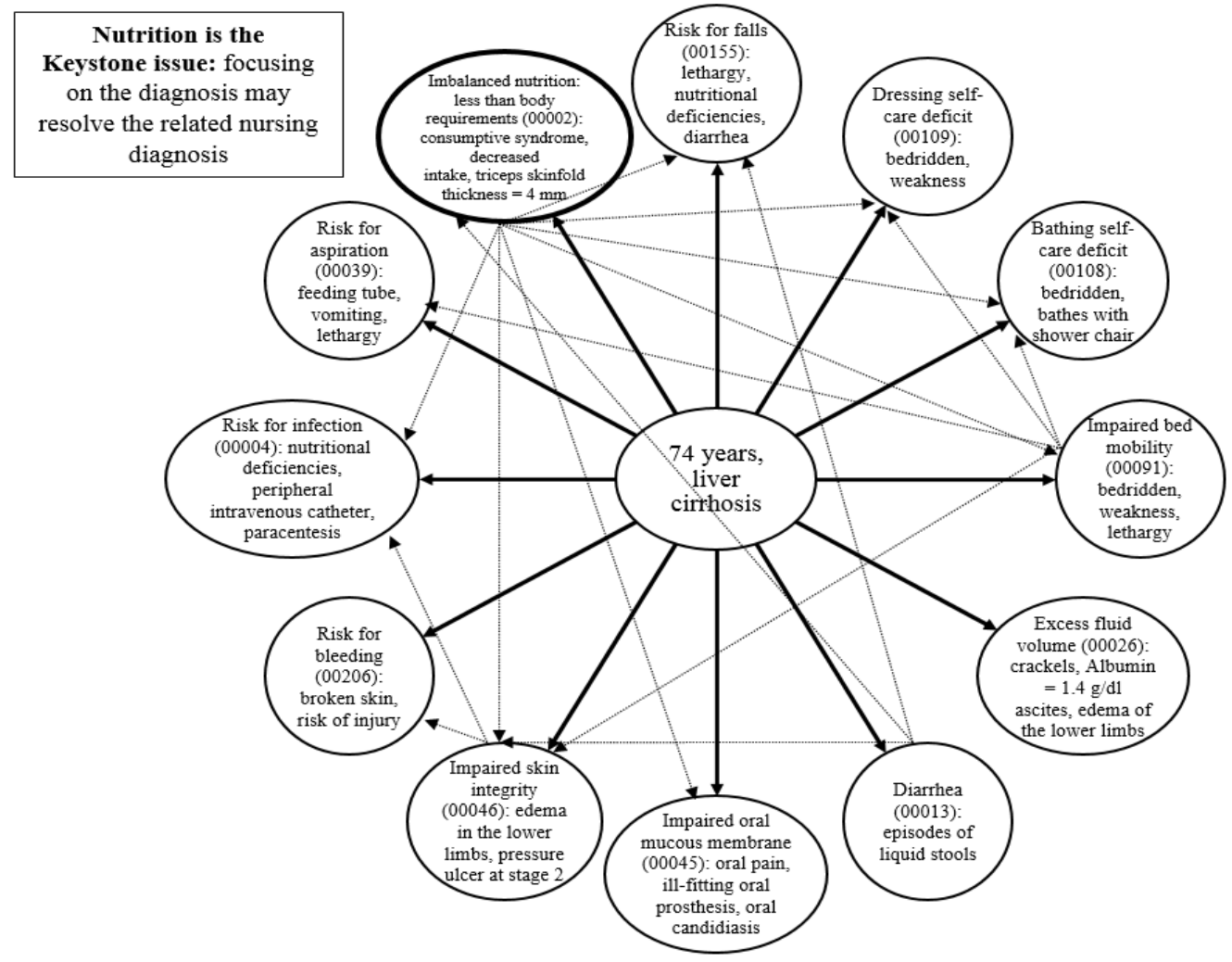

Fig1. Application of a clinical reasoning web in one patient with liver cirrhosis

Accordingly, the OPT model of clinical reasoning was used for the patient and it is shown in Figure 1.

NANDA-I, Inc. keystone issue was chosen for the patient was based on an analysis and synthesis of functional relationships among competing nursing diagnosis ${ }^{32}$. Thus, focus on the diagnosis Imbalanced nutrition: less than body requirements (00002) may resolve the related nursing diagnosis.

\section{NOC OUTCOMES}

The NOC outcomes proposed for patient were: Nutritional Status: Food and Fluid Intake (1008) with the indicators: tube feeding intake (100802) initially scored at " 1 " (not adequate) and with our target score set at "4" (substantially adequate); and intravenous fluid intake (100804) with the goal of maintaining the score set at " 2 " (slightly adequate). Another outcome identified was Weight: Body Mass (1006). The goal was to gain weight progressively and the baseline score for the indicator was " 1 " (several deviation from normal range), with our target score set at "3" (moderate deviation from normal range). The indicator triceps skin fold thickness (100602) was also determined, with a score initially set at " 1 ", but with a target score set for " 3 " 34 . 


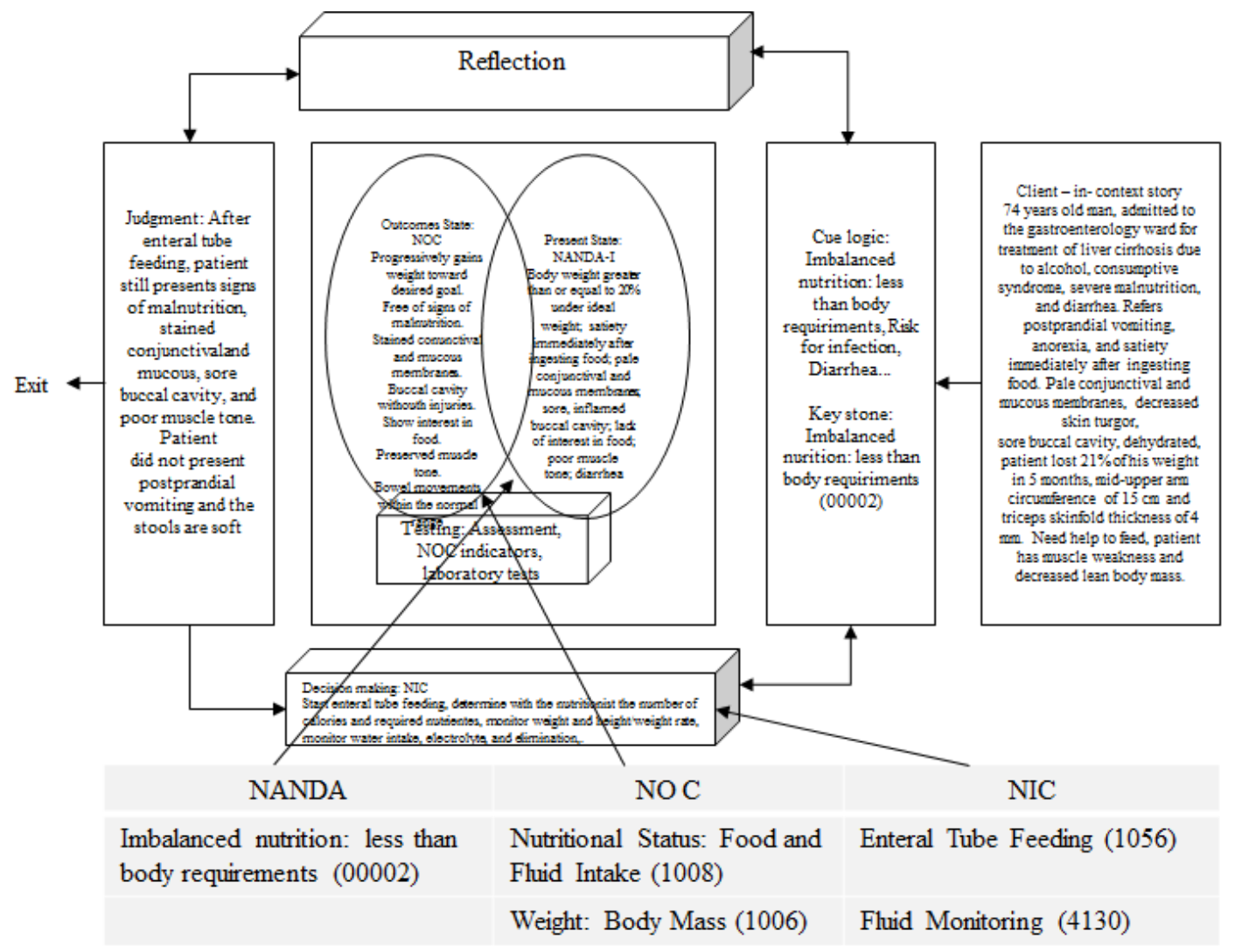

Fig2. OPT model of clinical reasoning in one patient with liver cirrhosis

The literature shows that malnutrition is widely described in patients with liver failure. However, there are few studies on the risk factors associated with weight loss, such as dehydration and malnutrition in people with liver cirrhosis $^{35}$. Liver cirrhosis has a major impact on patient's nutritional status because of the many factors contributing to the decrease food intake, such as early satiety due to ascites and gastrointestinal symptoms like nausea and vomiting. In addition, consumption of the restrictive diets are advised by making more severe the nutritional status ${ }^{36}$. The patient described in this case study shows similarity with the data described in the scientific literature that probably justify dehydration and malnutrition framework presented by patient in this case. Other possible causes include malnutrition, poor nutrients digestion and absorption related to chronic liver failure; as well as metabolic abnormalities such as hyper metabolism, macronutrients abnormal metabolism, increased secretion of catabolic hormones and reduced secretion of anabolic hormone ${ }^{37}$. It is worth to note that patient underwent several paracenteses relief procedures, as an intervention to relieve abdominal discomfort and ascites board. After conducting this intervention it was observed patient showed a moderate increase in skin hydration framework, with regression of edema and ascites.

\section{NIC INTERVENTIONS}

The first NIC intervention selected for the patient to achieve the outcomes was: Enteral Tube Feeding (1056), and the activities for this intervention included: insert a nasogastric tube, according to hospital protocol; monitor fluid and electrolyte status; consult with nutritionist in selecting the type and strength of enteral feeding; slow tube feeding rate and decrease strength to control diarrhea; monitor weight 3 times weekly initially, decreasing to once a month; monitor fluid intake and output; and monitor calorie, fat, carbohydrate, vitamin, and mineral intake for adequacy two times per week initially, decreasing to once a month. The enteral feeding tube, as well as evaluation by a nutritionist on the most appropriate diet for the patient, aimed to provide adequate nutritional support, minimizing the malnutrition profile presented by patient. The literature shows that malnutrition is a well-recognized condition in patients with liver cirrhosis. However, there is a controversy regarding the methods for its diagnosis due to the effects of liver disease in biochemical tests and body weight. In addition, weight loss during this period is difficult to evaluate because ascites, edema and risk factors for these conditions have not been well assessed ${ }^{35}$. Thus, the interventions (monitor fluid and electrolyte status) selected were justified. 
The second NIC intervention identified for the patient was Fluid Monitoring (4130) and the activities for this included: examine skin turgor; monitor weight; monitor intake and output; keep an accurate record of intake and output; monitor mucous membranes, skin turgor, and thirst; monitor color, quantity, and specific gravity of urine; and administer fluids as appropriate. Patient was monitored for weight and body fluids input and output. In addition, the characteristics of eliminations were recorded daily. The constant monitoring was essential because the hyper metabolism occurs in $16 \%-34 \%$ of patients with chronic liver disease ${ }^{38-40}$.

After 14 days, the nurse returned to complete a further assessment of patient. It was noted that after enteral tube feeding, patient still presented signs of malnutrition, stained conjunctival and mucous, sore buccal cavity, and poor muscle tone. However, patient did not present postprandial vomiting and the stools were soft. In addition, patient showed improvement in relation to diet acceptance, and decreased edema in the lower limbs. It is noteworthy that the nursing care provided to the patient gave relief and comfort, showing a physical and emotional improvement.

\section{CONCLUSION}

Effective clinical reasoning skills guide data collection, problem solving, decision-making, and provide quality care. It requires knowledge and abilities grounded in a theory and supported by evidence ${ }^{33,41}$. Therefore, nurses with effective clinical reasoning skills have a positive impact on patient outcomes ${ }^{23,41}$.

The strengths of this study included the use of clinical reasoning web to identify the priority focus of care based on an analysis and synthesis of functional relationship among competing nursing diagnosis. In addition, it is the first research conducted in a practice setting with patient with liver cirrhosis.

\section{REFERENCES}

[1] Kelso LA. Cirrhosis: Caring for Patients with End-stage Liver Failure. The Nurse Practitioner: The American Journal of Primary Health Care. 2008;33(7):6.

[2] Mokdad A, Lopez A, Shahraz S, et al. Liver cirrhosis mortality in 187 countries between 1980 and 2010: a systematic analysis. BMC Medicine. 2014;12(1):145.

[3] Galant LH, Forgiarini Junior LA, Dias AS, Marroni CA. Condição funcional, força muscular respiratória e qualidade de vida em pacientes cirróticos. Brazilian Journal of Physical Therapy. 2012;16:30-34.

[4] Barcelos S, Dias AS, Forgiarini Júnior LA, Monteiro MB. Transplante hepático: repercussões na capacidade pulmonar, condição funcional e qualidade de vida; Liver transplantation: effects in pulmonary capacity, functional condition and quality of life. Arq. gastroenterol. 2008;45(3):186-191.

[5] Carvalho EM, Isern MRM, Lima PA, Machado CS, Biagini AP, Massarollo PCB. Força muscular e mortalidade finalista de espera de transplante de fígado. Rev Bras Fisioter. 2008;12(3):235-240.

[6] Christensen PJ, Kenney JW. Nursing process: application of conceptual models. Mosby; 1995.

[7] Bosetti C, Levi F, Lucchini F, Zatonski WA, Negri E, La Vecchia C. Worldwide mortality from cirrhosis: an update to 2002. Journal of hepatology. 2007;46(5):827-839.

[8] Leon DA, McCambridge J. Liver cirrhosis mortality rates in Britain from 1950 to 2002: an analysis of routine data. The Lancet. 2006;367(9504):52-56.

[9] Goncalves CB, Moreira LB, Gus M, Fuchs FD. Adverse events of blood-pressure-lowering drugs: evidence of high incidence in a clinical setting. Eur J Clin Pharmacol. 2007;63(10):973-978.

[10] Gonçalves PL, Gonçalves CS, Pereira FEL. Mortality from liver cirrhosis in Espírito Santo State, Brazil. Cadernos de Saúde Pública. 2014;30(6):1335-1340.

[11] Goncalves PL, Zago-Gomes MdP, Marques CC, Mendonça AT, Gonçalves CS, Pereira FEL. Etiology of liver cirrhosis in Brazil: chronic alcoholism and hepatitis viruses in liver cirrhosis diagnosed in the state of Espfrito Santo. Clinics. 2013;68(3):291-295.

[12] Portugal FB, Campos MR, Carvalho JRd, Flor LS, Schramm JMdA, Costa MdFdS. Disease burden in Brazil: an investigation into alcohol and non-viral cirrhosis. Ciencia \& saude coletiva. 2015;20(2):491-501.

[13] Brasil MdS. Saúde Brasil 2007: uma análise da situação de saúde. Brasília2008.

[14] Silva ISS. Cirrose hepática. Revista Brasileira de Medicina. 2010;67(4):9.

[15] Brasil MdS. Cadernos de informações de saúde. In: DATASUS, ed. Brasília: Ministério da Saúde; 2010.

[16] Barros MBdA, Francisco PMSB, Zanchetta LM, César CLG. Tendências das desigualdades sociais e demográficas na prevalência de doenças crônicas no Brasil, PNAD: 2003- 2008. Ciência \& Saúde Coletiva. 2011;16:3755-3768.

[17] Boonstra K, Kunst AE, Stadhouders PH, et al. Rising incidence and prevalence of primary biliary cirrhosis: a large population-based study. Liver International. 2014;34(6):e31-e38. 
[18] Singal AK, Salameh H, Kamath PS. Prevalence and in-hospital mortality trends of infections among patients with cirrhosis: a nationwide study of hospitalised patients in the United States. Alimentary Pharmacology \& Therapeutics. 2014;40(1):105-112.

[19] Rossi LA, Santos CMdNMdA, Ferreira E, Dalri MCB, Carlucci VDdS. Diagnósticos de enfermagem presentes em familiares de pacientes vítimas de queimaduras. Revista da Escola de Enfermagem da USP. 2006;40:356-364.

[20] Scherb CA, Head BJ, Maas ML, et al. Most Frequent Nursing Diagnoses, Nursing Interventions, and Nursing-Sensitive Patient Outcomes of Hospitalized Older Adults With Heart Failure: Part 1. International Journal of Nursing Terminologies and Classifications. 2011;22(1):13-22.

[21] Ouslander JG, Diaz S, Hain D, Tappen R. Frequency and Diagnoses Associated With 7- and 30-Day Readmission of Skilled Nursing Facility Patients to a Nonteaching Community Hospital. Journal of the American Medical Directors Association. 2011;12(3):195-203.

[22] Souza CCd, Mata LRFd, Carvalho ECd, Chianca TCM. Diagnósticos de enfermagem em pacientes classificados nos níveis I e II de prioridade do Protocolo Manchester. Revista da Escola de Enfermagem da USP. 2013;47:1318-1324.

[23] Simmons B, Lanuza D, Fonteyn M, Hicks F, Holm K. Clinical reasoning in experienced nurses. West J Nurs Res. 2003;25(6):701-719; discussion 720-704.

[24] Horta WdA. Processo de enfermagem. São Paulo: E.P.U.; 1979.Maslow AH. A theory of human motivation. Psychological Review. 1943;50(4):370-396.

[25] Park H. NANDA-I, NOC, and NIC linkages in nursing care plans for hospitalized patients with congestive heart failure. Univerity of Iowa, Univerity of Iowa; 2010.

[26] Daniel JP, Herman JA. Clinical reasoning: the art and science of critical and creative thinking. Delmar; 1999.

[27] Kautz DD, Kuiper R, Pesut DJ, Williams RL. Using NANDA, NIC, and NOC (NNN) language for clinical reasoning with the Outcome-Present State-Test (OPT) model. Int J Nurs Terminol Classif. 2006;17(3):129-138.

[28] Pesut DJ, Herman J. OPT: transformation of nursing process for contemporary practice. Nurs Outlook. 1998;46(1):29-36.

[29] Simmons B. Clinical reasoning: concept analysis. Journal of Advanced Nursing. 2010;66(5):1151-1158.

[30] Johnson M, North American Nursing Diagnosis A. NANDA, NOC, and NIC linkages: nursing diagnoses, outcomes, \& interventions. Mosby Elsevier; 2006.

[31] Kuiper R, Heinrich C, Matthias A, Graham MJ, Bell-Kotwall L. Debriefing with the OPT model of clinical reasoning during high fidelity patient simulation. Int J Nurs Educ Scholarsh. 2008;5:Article17.

[32] Kautz DD, Kuiper R, Pesut DJ, Knight-Brown P, Daneker D. Promoting clinical reasoning in undergraduate nursing students: application and evaluation of the Outcome Present State Test (OPT) model of clinical reasoning. Int J Nurs Educ Scholarsh. 2005;2:Article 1.

[33] Moorhead S, Johnson M, Maas ML, Swanson E. Nursing Outcomes Classification (NOC),Measurement of Health Outcomes,5: Nursing Outcomes Classification (NOC). Elsevier/Mosby; 2013.

[34] Anastácio LR, Ferreira LG, Ribeiro HdS, Lima AS, Vilela EG, Correia MITD. Weight loss during cirrhosis is related to the etiology of liver disease. Arquivos de Gastroenterologia. 2012;49:195-198.

[35] Heyman JK, Whitfield CJ, Brock KE, McCaughan GW, Donaghy AJ. Dietary protein intakes in patients with hepatic encephalopathy and cirrhosis: current practice in NSW and ACT. Medical journal of Australia. 2006;185(10):542.

[36] Henkel AS, Buchman AL. Nutritional support in patients with chronic liver disease. Nature Clinical Practice Gastroenterology \& Hepatology. 2006;3(4):202-209.

[37] Sam J, Nguyen GC. Protein-calorie malnutrition as a prognostic indicator of mortality among patients hospitalized with cirrhosis and portal hypertension. Liver International. 2009;29(9):1396-1402.

[38] Ritter L, Gazzola J. Avaliação nutricional no paciente cirrótico: uma abordagem objetiva, subjetiva ou multicompartimental? Arquivos de Gastroenterologia. 2006;43:66-70.

[39] PORT GZ, OLIVEIRA K, SOLDERA J, TOVO CV. BIOCHEMICAL NUTRITIONAL PROFILE OF LIVER CIRRHOSIS PATIENTS WITH HEPATOCELLULAR CARCINOMA. Arquivos de gastroenterologia. 2014;51(1):10-15.

[40] Levett-Jones T, Hoffman K, Bourgeois S, et al. Clinical reasoning. Instructor resources. University of Newcastle: School of Nursing and Midwifery Faculty of Health; 2009. 